WellBeing International

WBI Studies Repository

7-2007

\title{
Observing Panda Play: Implications for Zoo Programming and Conservation Efforts
}

\author{
Sarah M. Bexell \\ Chengdu Research Base of Giant Panda Breeding \\ Olga S. Jarrett \\ Georgia State University \\ Luo Lan \\ Chengdu Research Base of Giant Panda Breeding \\ $\mathrm{Hu}$ Yan \\ Chengdu Zoo \\ Estelle A. Sandhaus \\ Santa Barbara Zoo
}

See next page for additional authors

Follow this and additional works at: https://www.wellbeingintlstudiesrepository.org/acwp_zoae

Part of the Animal Studies Commons, Nature and Society Relations Commons, and the Population Biology Commons

\section{Recommended Citation}

Bexell, S. M., Jarrett, O. S., Lan, L., Yan, H., Sandhaus, E. A., Zhihe, Z., \& Maple, T. L. (2007). Observing Panda play: implications for Zoo programming and conservation efforts. Curator: The Museum Journal, 50(3), 287-297.

This material is brought to you for free and open access by WellBeing International. It has been accepted for inclusion by an authorized administrator of the WBI Studies Repository. For more information, please contact wbisr-info@wellbeingintl.org.

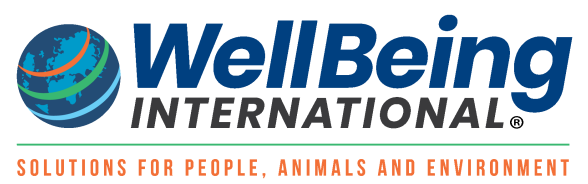


Authors

Sarah M. Bexell, Olga S. Jarrett, Luo Lan, Hu Yan, Estelle A. Sandhaus, Zhang Zhihe, and Terry L. Maple 


\title{
Observing Panda Play: Implications for Zoo Programming and Conservation Efforts
}

\author{
Sarah M. Bexell, ${ }^{1}$ Olga S. Jarrett, ${ }^{2}$ Luo Lan, ${ }^{1} \mathrm{Hu}$ Yan, ${ }^{3}$ Estelle A. Sandhaus, ${ }^{4}$ Zhang Zhihe, ${ }^{1}$ \\ Terry L. Maple ${ }^{5}$ \\ ${ }^{1}$ Chengdu Research Base of Giant Panda Breeding \\ ${ }^{2}$ Georgia State University \\ ${ }^{3}$ Chengdu Zoo \\ ${ }^{4}$ Santa Barbara Zoo \\ ${ }^{5}$ Georgia Institute of Technology
}

\begin{abstract}
This study explores the effects of visitor observation of giant panda play on visitor concern for endangered species and satisfaction with seeing giant pandas. A total of 335 visitors to three institutions that house giant pandas participated in the study. These institutions are: the Chengdu Research Base of Giant Panda Breeding, and the Chengdu Zoo, in China; and Zoo Atlanta in the U.S. After viewing the giant pandas, visitors were interviewed on whether they ever observed a panda play session, whether they observed panda play on the day of the visit, whether they wanted additional information on panda protection, and how satisfied they were with their visit to the pandas. An informational flyer was given to each interested survey participant after the interview. Visitors did not differ in their request for conservation information according to whether they had ever seen pandas play. However, visitors who observed panda play on the day of their visit expressed greater satisfaction with their visit. Implications for zoos and their conservation efforts are discussed.
\end{abstract}

Humans have long been intrigued by non-human animal (hereafter animal) play. Scientists study animal play to investigate its significance in physical, cognitive, and social development. ${ }^{1}$ Research reveals that play may be important for development of species appropriate behavior with implications for conservation and animal well-being. Visitors to zoos often remark that they enjoy seeing animals such as monkeys or otters because they frequently play. Why is it that humans are so drawn to the playful antics of other species? Is it because they identify something they know is pleasurable in their own lives? Are humans interested in animal play because they learn from it? What can humans learn from a casual observation of a play session? Does such an observation change their feelings or attitudes about the animal?

Throughout evolutionary history, the role that animals play in the lives and thoughts of humans has always been important. ${ }^{2}$ Humans and other animals have historically taken on a diverse array of roles in relation to one another-predators, prey, parasites, competitors, companions, laborers, guards, and entertainers, for instance. Animals have meant even more to people than this, however. They have become a part of how we think about the world emotionally and intellectually, and have served as deities, models of conduct, and symbols of art, literature, and myth (Shepard 1996). Being objective about our 
relationships with animals is difficult and sometimes controversial. There are many personal opinions about the levels of welfare afforded to animals, as well as levels of attachment to animals. However, it is important for us, and for the future of wildlife, to attempt to be objective about our relationships with animals. Animals assist us in creating our sense of self in relation to the world (Myers 2007). Human life is dependent on Earth's biodiversity. Therefore it is critical that we understand our relationships with other living things, develop a sustainable lifestyle, and preserve the life forms and forces that sustain us.

Throughout history, people have tried to understand animals (Lockwood 1989). Two things that have a strong influence on how humans view wild animals are: a) the direct effects animals can have on humans, and b) anthropomorphism. A short list of these direct effects includes being part of the food chain: for instance, animals serve as food for humans and, especially in the past, as predators of humans. Animals provide countless ecological services to humans: such as pollination, decomposition and recycling of waste, and control of agricultural pests. Some animals provide medicines directly from their bodies. Some give us clues to new medicinal compounds found in their environment from observation of their behavior. Animals are also one of humanity's strongest forms of spiritual, cultural, and personal inspiration and rejuvenation.

The tendency to anthropomorphize animals affects human perception of animals. Anthropomorphism is the projection of human traits onto animals, which seems to make them more understandable, and often more likeable. Our perceptions and attitudes affect our interactions with animals and in turn our impact on the natural world.

Individual people possess their own set of beliefs and attitudes about animals, animal rights, and factors that will influence a concern for these animals (Kalof 2002). Therefore, visitors to captive animal facilities such as zoos might interact differently with animal exhibits and conservation concerns presented within the facility. Their personal beliefs may work within, or contrast with, belief systems presented with regard to human responsibility to wildlife. Therefore the level of impact a zoo experience has on an individual's conservation concern will be different for each visitor. Investigators have suggested a number of particularly important factors in human preference for different animals (Kellert 1989). These include:

1. Size (usually, the larger the animal, the more preferred).

2. Aesthetics (considered "attractive").

3. Intelligence (thought to have the capacity not only for reason but also for feeling and emotion).

4. Danger to humans (non-threatening is preferred).

5. Likelihood of inflicting property damage (for example, termites are not welcomed into our homes).

6. Predatory tendencies (animals that do not prey on humans, our pets or livestock are preferred).

7. Phylogenetic relatedness to humans (animals such as the great apes are preferred because they are more closely related to, and at the same time more like, humans).

8. Cultural and historical relationships to humans (for example bald eagles are important to Americans as the national symbol of the United States).

9. Relationship to human society (pets, domestic farm animals, game, pests, native wildlife, exotic wildlife). 
10. Texture (bodily appearance and structure; generally, the more unfamiliar to humans, the less preferred).

11. Mode of locomotion (generally, the more unfamiliar to humans, the less preferred).

12. Economic value of the species to humans (if their existence is of economic benefit to humans, such as bees for pollination of crops, they are more preferred).

While some of these factors could induce a negative attitude toward some species, many could promote positive attitudes and respect. Even some negative human attitudes such as fear greatly increase human interest-for example, human fascination with sharks. Kellert found that a great deal of interest in animals, as well as affection and concern for them, is present in humans (1989). However, until human attitudes, including self-interest and self-sustenance at the expense of others, can be better understood, it is doubtful that the destruction of nature and wildlife can be avoided (Song 2004).

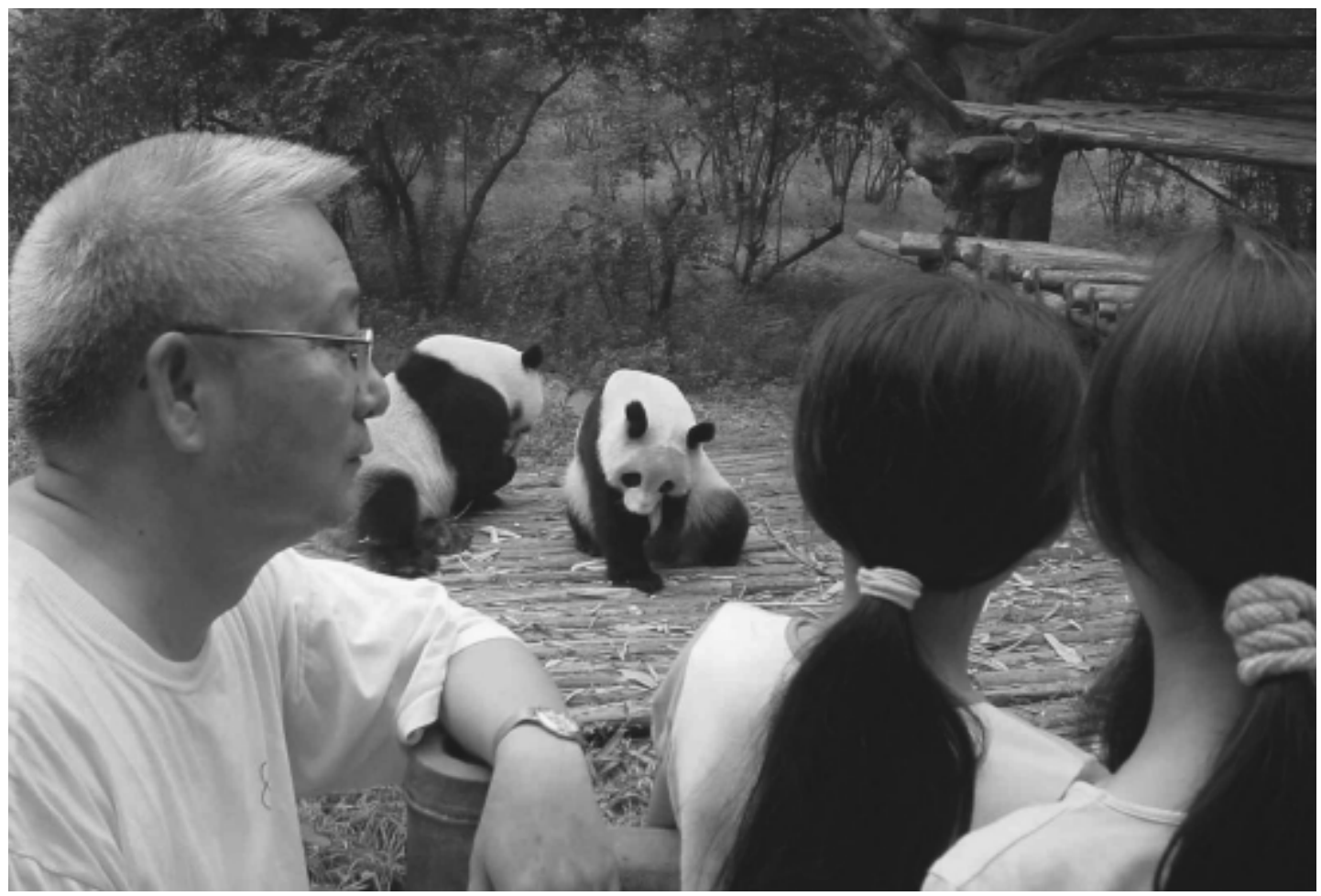

Watching giant pandas eating at the Chengdu Research Base. Photo by Sarah M. Bexell.

One interesting way humans form an emotional orientation toward animals is to connect with their youthful traits (Lawrence 1989; Russow 1989). The term neoteny is used to describe the retention of youthful traits into adulthood in animals. Humans seem to connect with the youthful traits of giant pandas with ease (Morris and Morris 1982). In humans, neoteny is a biological characteristic, as well as a psychological (behavioral) and physical condition. This retention of youthful traits is seen in the prolonged childhood of humans in terms of both our social and biological characteristics. Lorenz described an innate human parental-care response to animals with neotenous features (1981). He proposed that the physical configuration of a high and slightly bulging forehead, large brain case in proportion to the face, big eyes, rounded cheeks, and short, stubby limbs elicits in humans a nurturing response and feelings of compassion. A study of helping behavior toward humans with juvenile versus mature faces indicated that neotenous appearance of human faces promoted more helping behaviors toward white males, white 
females, and black females (Keating, Randall, Kendrick, and Gutshall 2003). Humans seem to have an affinity for these characteristics when they perceive them in other species (Fullard and Reiling 1976; Lawrence 1989). For instance, Disney's Bambi, with his huge head and oversized eyes with pupils and lashes, arouses sentiment. So do giant pandas, with their large heads, round cheeks, large eyes (appearing larger due to surrounding black fur eye patches), fat, stubby limbs and playful nature. Pandas arouse a distinct passion in most humans (Morris and Morris 1982). The neotenous behavior of play in animals is easy for humans to anthropomorphize because childlike behavior is something all humans are familiar with and can relate to. Neotenous traits also appear to arouse the sentiment that we as humans have some sort of responsibility toward such species, due to our more developed rationality. This view of animals as disadvantaged and needful can be found in children's literature dealing with our responsibilities toward wildlife (Melson 2001; Fudge 2002). Animals perceived as having more youthful traits may be more likely to elicit a positive emotional response and perhaps even more protection than less youthful-appearing animals.

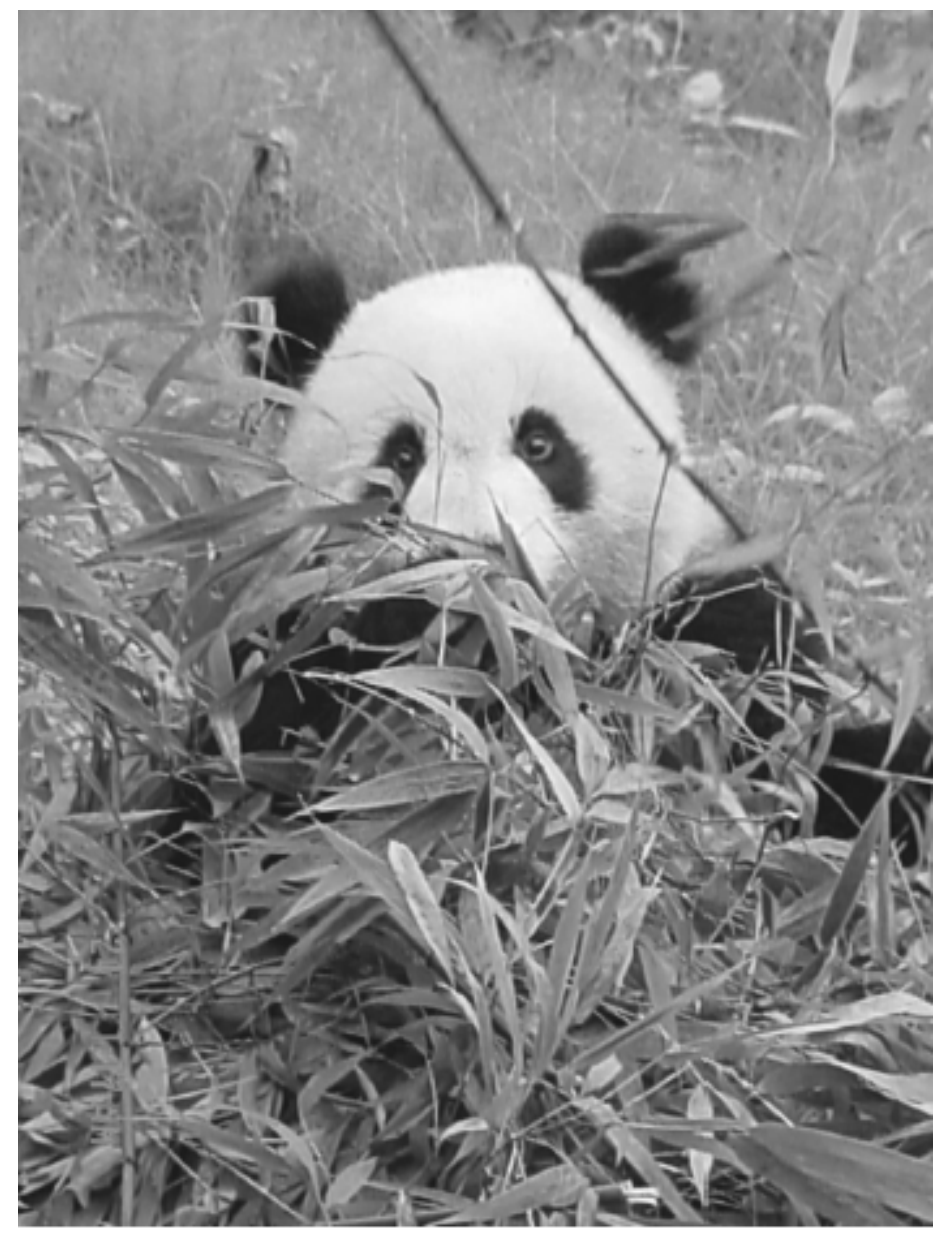

Subadult female giant panda showing characteristic facial features. Photo by Sarah M. Bexell.

Behavior such as play can also be classified as a youthful trait. According to Lancy (1980), high rates of play in captive adult animals represent a case of neoteny (youthful traits) in behavior. Some aspects of mammalian behavior are as appealing as cute looks, so play behavior may also attract humans to more playful animals. Even animals that are not typically perceived as especially attractive seem to become irresistible when we become enchanted with their awkward, playful actions (Burghardt and Herzog 1989). Animals that play seem to be valued more than those that do not, especially if it is easy to interpret the 
behavior as play (Burghardt and Herzog 1989). Our attraction to these attributes could be based on predispositions to attend to juvenile humans.

In a visitor study done at the National Zoo, snakes and other reptiles were found to be the most disliked animals, while the most preferred were giant pandas (Hoage 1989). Giant pandas are often described as cute, cuddly, and adorable. Giant pandas would certainly be considered appearing youthful, both in appearance and playfulness, while reptiles, which appear very much like miniature adults even upon hatching, would not.

Humans may also identify with playing animals because play is a behavior we share in common with animals (Power 2000; Mitchell 2002). Animals seem to enjoy play enormously (Bekoff 2000) and neurobiological studies of the chemistry of play offer support that it is highly pleasurable for animals (Panksepp 1998). Play is a behavior humans understand and that we associate with pleasure. While some scientists are skeptical that animals have emotional lives, even the most hard-nosed scientist may find it easier to associate play with a positive emotional state than to deny an emotional state exists at all (Bekoff 2000). Perhaps when humans observe animal play they also feel a strong sense of pleasure.

The theory surrounding perceptions of animal play and the retention of youthful traits into adulthood in pandas led us to investigate the potential relationship between visitors' viewing of panda play, visitor satisfaction with the experience of observing the pandas, and interest in giant panda conservation. Our hypothesis was that observing play behavior would help the visitor connect with the pandas and increase interest in panda conservation. Also we hypothesized that watching panda play would significantly enhance visitors' experience of panda-watching. Having chosen a neotenous species for this study, we note that play behavior is an additive effect contributing to the youthful appearance of giant pandas. All visitors in this study would probably be attracted to the appearance of giant pandas, but we were looking at whether the play (a neotenous behavior) of the giant pandas added another set of incentives to inducing interest and conservation concern in visitors who witnessed play.

\section{Method}

Survey data was collected in three different settings in two countries. The same visitor survey was administered in Sichuan Province of the Peoples Republic of China, at two sites, the Chengdu Zoo and the Chengdu Research Base of Giant Panda Breeding (henceforth referred to as the Research Base); and in Atlanta, Georgia, at Zoo Atlanta. These three facilities were chosen because they all house giant pandas and were accessible to the first author. The Research Base is a naturalistic facility built for captive breeding and research on Giant Pandas and several other Chinese endangered species; it attracts many foreign as well as domestic visitors. The Chengdu Zoo is a typical Chinese zoo with high diversity of animals and very high visitorship, mostly domestic. Zoo Atlanta is a small zoo with an emphasis on naturalistic housing of animals, research, and conservation, and is home to two giant pandas on loan from China (they were joined by a cub after the research was conducted). The three settings differ in their exhibit style, visitorship, and overall mission; at all three sites, however, the focus of this research was on seeing giant pandas play.

The research reported here was from a larger survey that examined relationships between visitors' experience of giant pandas, interest in conservation, and the zoo experience. The first author trained volunteers in each setting to administer the survey orally to visitors, in English in Atlanta and in Chinese in Chengdu. Play was not defined for the survey participants to avoid influencing their responses. Volunteers were told to make sure that visitors had already seen giant pandas that day before asking them to participate in the survey. The volunteers read the questions and recorded the visitors' answers. The following questions were used in this research, listed in the order in which they were asked: 
1. Have you ever seen a giant panda before today? Yes No

If you have seen a giant panda before, what was it doing? (Check all that apply.)

Playing Fighting Sleeping Eating Other (specify)

2. Please rate the quality of your experience seeing the giant pandas today, according to the following scale: 1 = poor, 2 = fair, 3 = satisfactory, 4 = good, $5=$ excellent. Why?

3. What were the pandas doing while you were watching them today? (Check all that apply.) Playing Fighting Sleeping Eating Other (specify)

4. Would you like to learn how you can do something to help save giant pandas? Yes No

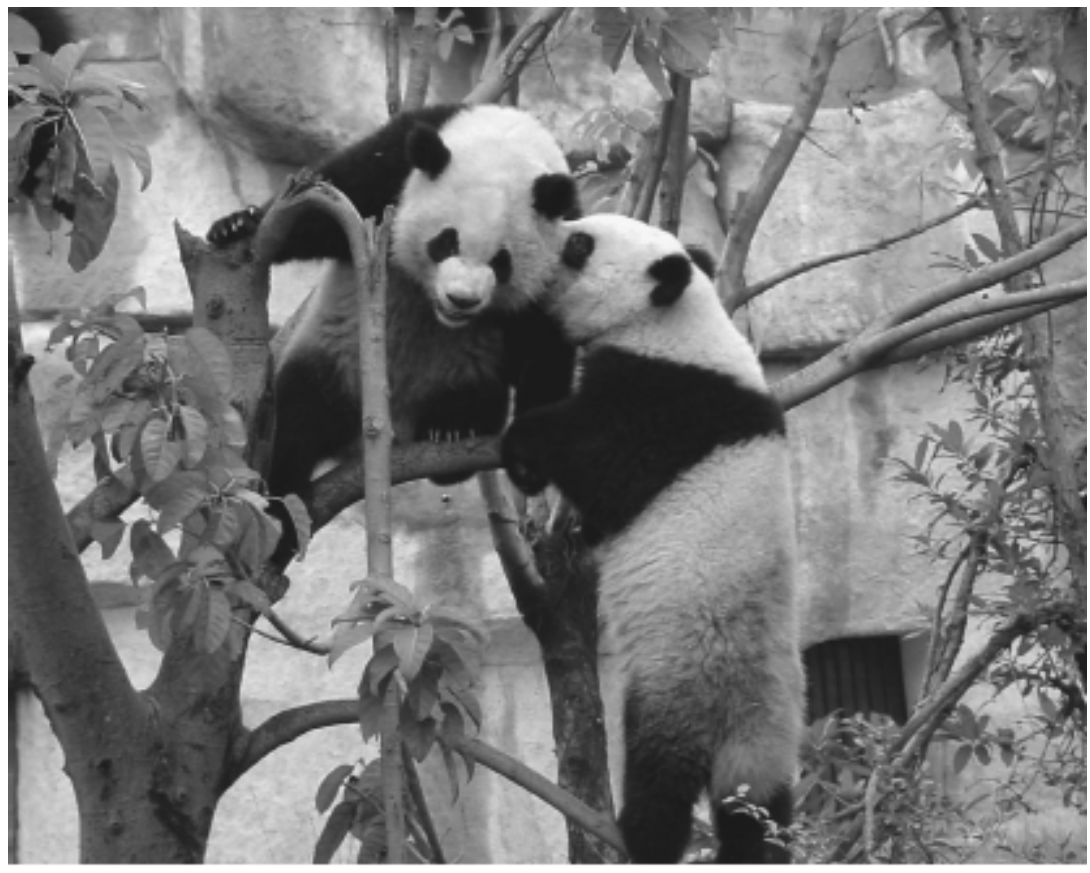

Two juvenile giant pandas wrestle in a tree at the Chengdu Research Base of Giant Panda Breeding. Photo by Sarah M. Bexell.

Those who said yes to question four received a flyer with panda conservation information. In all, 190 visitors at the Research Base, 81 visitors at Zoo Atlanta, and 64 visitors at the Chengdu Zoo answered the four questions above. Answers to questions 1 and 3 were combined to determine whether the visitor had ever seen pandas at play.

\section{Results}

To determine whether visitors who had ever seen pandas at play were more interested in panda conservation, the answers of the visitors at the three facilities were compared. At the Research Base, 86 percent of those who had seen pandas play (compared to 84 percent of those who had not seen pandas play) wanted conservation information. At the Chengdu Zoo, 96 percent of those who had and 92 percent 
of those who had not seen pandas playing wanted information. At Zoo Atlanta, all of those who saw pandas playing asked for information, compared to 79 percent of those who did not see play. The trends were as expected but an Analysis of Variance statistical test found no significant differences between zoos and no significant differences among visitors who had ever seen pandas playing.

In order to ascertain whether people rated their experience more highly if they saw pandas play on the day that they were surveyed, an independent samples $t$-test was computed with "seeing panda play that day" as the independent variable and "rating of satisfaction with seeing the pandas" as the dependent variable. Visitors who had seen panda play were significantly more satisfied with their panda viewing experience $(t(353)=3.64, p<.001)$ than were visitors who had not seen panda play. The 22 percent of the visitors who had seen the pandas play that day rated their experiences as 4.34 on a five point Likert scale, whereas those who had not seen the pandas play rated their experience as 3.86 .

\section{Discussion}

We did not find a significant link between the observation of panda play and the desire to learn more about how to save the giant panda. A high percentage of visitors in China with both play-watching and non-play-watching experiences said they would like to learn how they can do something to help save giant pandas, a result that may be attributable to the fact that the Chinese are taught to see pandas as a national treasure. It is fortunate that people in China already care deeply about giant pandas. At Zoo Atlanta, a small percentage of visitors (20 percent) observed the pandas at play. All of these visitors requested more information, which may suggest that play helped them connect with the pandas. In contrast, the Zoo Atlanta visitors who watched the pandas sleep or eat, but not play, exhibited the lowest percentage of information requests. We recommend more research with larger sample sizes and additional institutions to determine whether this possible trend is in fact indicative of experience-action differences among American visitors.

In the second analysis, the data support the idea that people enjoy seeing the pandas more if they see them play. This finding may have important implications for zoo planning, since visitor satisfaction can manifest itself in return visits and memberships as well as in support for zoo conservation efforts. Obviously, animals-whether pandas, tiger cubs, gorillas, or otters-cannot be forced to play. However, animal habitats can be arranged so that visitors can better observe animal play, and school groups can be scheduled to visit animal viewing areas at times when the animals are more likely to play. At the time of data collection at Zoo Atlanta, the two pandas were allowed to interact together for about an hour in the morning. Much of what could be described as play occurred during the time the pandas were together, but at least part of that time was generally scheduled before the zoo opened. By changing the schedule slightly, the zoo would have allowed more visitors to see the pandas play. Another strategy used by conscientious zoos today to promote activity and natural behaviors in their animals is the provision of species-appropriate enrichment (Rooney and Sleeman 1998): for example, hiding seeds or nuts in hay or shredded paper so the animals have the opportunity to hunt for treats. Providing enrichment for animals during peak visitation hours could promote interest in and understanding of the animals.

There were several weaknesses in this study. One is that the entire survey, of which only a part is reported here, may have been too long, as indicated by participant attrition (many visitors became impatient with the length of time it took to complete the survey and excused themselves before answering all the questions). In order to obtain more data on this paper's specific research questions, a short, more precise survey might have yielded better completion rates. Another weakness was the large number of volunteers who conducted the survey (over 100), which made it logistically impossible to ensure interrater reliability. 
We have several ideas for future research. Because an attachment to animals seems to be stronger and even more natural in young children (Myers 2007), a survey will be designed asking similar but ageappropriate questions of young children. Children may also be interviewed on the following points after seeing videos of endangered animals at play or engaged in other behaviors: a) how it made them feel, b) how it made them feel about the animal, c) what they learned from watching the video, and d) whether they are concerned about the survival of the animal.

How wildlife is to be managed in the future depends on why it is thought important for wildlife to have a future (Cooper 1999). There have always been people-among them Gandhi and George Bernard Shaw-concerned about humane treatment of animals. But only the recent massively visible threat to wildlife has resulted in serious efforts to construct a "wildlife ethic" as an extension to the established moral thinking, which used to apply primarily only to human beings. Play may be a way to connect people to animals in order to help them commit to wildlife protection.

\section{Acknowledgments}

The authors wish to thank John Fraser, director of Public Research and Evaluation, Wildlife Conservation Society, New York, for his constructive feedback on an earlier draft of this paper. We appreciate his belief in the importance of the paper as well as his useful suggestions and provision of additional references. These were incorporated into the final version.

\section{Notes}

1. For physical development see Bekoff and Byers (1992); Power (2000); and Wilson (2005). For cognitive development see West (1977); Thompson (1998); Power (2000). For social development see Fagen (1981); Power (2000).

2. See Shepard (1978; 1996); Wilson (1984); Challinor (1989); Kellert (1989); Hindley (1999).

\section{References}

Bekoff, M. 2000. Animal emotions: Exploring passion and nature. Bioscience 50 (10): 861-870.

Bekoff, M., and J. A. Byers. 1992. Time, energy and play. Animal Behavior 44: 981-982.

Burghardt, G. M., and H. A. Herzog. 1989. Animals, evolution, and ethics. In Perceptions of Animals in American Culture, R. J. Hoage, ed., 129-151. Washington, DC: Smithsonian Institution Press.

Challinor, D. 1989. Contrasting viewpoints. In Perceptions of Animals in American Culture, R. J. Hoage, ed., 25-40. Washington, DC: Smithsonian Institution Press.

Cooper, D. E. 1999. Human sentiment and the future of wildlife. In Attitudes to Animals, F. L. Dolins, ed., 231-243. Cambridge: Cambridge University Press.

Fagen, R. 1981. Animal Play Behavior. New York: Oxford University Press.

Hindley, M. P. 1999. "Minding animals": The role of animals in children's mental development. In Attitudes to Animals, F. L. Dolins, ed., 186-199. Cambridge, UK: Cambridge University Press.

Hoage, R. J. 1989. Introduction. In Perceptions of Animals in American Culture, R. J. Hoage, ed., 1-4. Washington, DC: Smithsonian Institution Press. 
Kalof, L. 2002. The multi-layered discourses of animal concern. In Social Discourse and Environmental Policy, H. Addams and J. Stroop, eds., 174-195. Cheltenham, UK: Edward Elgar.

Keating, C. F., D. W. Randall, T. Kendrick, and K. A. Gutshall. 2003. Do babyfaced adults receive more help? The (cross-cultural) case of the lost resume. Journal of Nonverbal Behavior 27 (2): 89.

Kellert, S. R. 1989. Perceptions of animals in America. In Perceptions of Animals in American Culture, R. J. Hoage, ed., 5-24. Washington, DC: Smithsonian Institution Press.

Lancey, D. F. 1980. Play in species adaptation. Annual Review of Anthropology 9: 471-495.

Lawrence, E. A. 1989. Neoteny in American perceptions of animals. In Perceptions of Animals in American Culture, R. J. Hoage, ed., 57-76. Washington, DC: Smithsonian Institution Press.

Lockwood, R. 1989. Anthropomorphism is not a four-letter word. In Perceptions of Animals in American Culture, R. J. Hoage, ed., 41-56. Washington, DC: Smithsonian Institution Press.

Lorenz, K. 1981. The Foundations of Ethology. New York: Simon and Schuster.

Melson, G. F. 2001. Why the Wild Things Are: Animals in the Lives of Children. Cambridge: Harvard University Press.

Mitchell, R. W., ed. 2002. Pretending and Imagination in Animals and Children. New York: Cambridge University Press.

Morris, R., and D. Morris. 1982. The Giant Panda. London: Penguin Books.

Myers, Gene. 2007. The Significance of Children and Animals: Social Development and Our Connections to Other Species. West Lafayette, IN: Purdue University Press.

Panksepp, J. 1998. Affective Neuroscience. New York: Oxford University Press.

Power, T. G. 2000. Play and Exploration in Children and Animals. Mahwah, NJ: Lawrence Erlbaum Associates.

Rooney, M. B., and J. Sleeman. 1998. Effects of selected behavioral enrichment devices on behavior of Western lowland gorillas (Gorilla gorilla gorilla). Journal of Applied Animal Welfare Science 1 (4): 339-351.

Russow, L.-M. 1989. Changing perceptions of animals: A philosophical view. In Perceptions of Animals in American Culture, R. J. Hoage, ed., 25-40. Washington, DC: Smithsonian Institution Press.

Shepard, P. 1978. Thinking Animals. New York: Viking Press.

. 1996. The Others: How Animals Made Us Human. Washington, DC: Shearwater Books.

Song, W. 2004. Traditional Chinese culture poses difficulty for new animal welfare laws. Animal Legal and Historical Center. Accessed June 14, 2005 at www.animallaw.info/articles/archsongculture2004.htm.

Thompson, K. V. 1998. Self assessments in juvenile play. In Animal Play: Evolutionary, Comparative, and Ecological Perspectives, M. Bekoff and J. A. Byers, eds., 183-204. New York: Cambridge University Press. 
West, M. J. 1977. Exploration and play with objects in domestic kittens. Developmental Psychobiology 10 (1): 53-57.

Wilson, E. O. 1984. Biophilia: The Human Bond with Other Species. Cambridge, MA: Harvard University Press.

Wilson, M. L. 2005. An investigation into the factors that affect play fighting behavior in giant pandas. Ph.D. dissertation, Georgia Institute of Technology. 